\title{
Exploration and Thinking of Ideological and Political Theories Teaching in College English
}

\author{
Shi Xiaolin ${ }^{1, a}$ \\ ${ }^{1}$ Air Force Aviation University \\ a460505811@qq.com

\begin{abstract}
College English, as a compulsory course in general education, is also an important course in ideological and political theories teaching. When designing English courses, teachers are supposed to consider multi-angle and all-round thinking, especially focusing on excavating ideological and political elements in traditional Chinese culture, Xi Jinping's thought on socialism with Chinese Characteristics for a new era, thinking mode and thinking ability, occupation identity and mission. The integration of course contents with ideological and political elements will help cultivate new-age college students who can tell Chinese stories to the world.
\end{abstract}

Keywords: College English; ideological and political theories teaching; ideological and political elements

\section{大学英语课程思政元素的挖掘与思考}

\author{
史晓琳 $1, \mathrm{a}$
}

\footnotetext{
1 空军航空大学

a460505811@qq.com
}

\section{摘要}

大学英语作为学生通识教育阶段的必修课程, 也是开展课程思政的重要学科。教师在设计大学英语课程思政内 容时，应注意进行多角度、全方位的思考，尤其注重中国传统文化方面、习近平新时代中国特色社会主义思想 方面、思维方式及思考能力方面、职业身份及使命担当方面思政元素的挖掘,将课程内容与思政元素自然融合, 助力培养能够面向世界讲好中国故事的新时代大学生。

关键词: 大学英语；课程思政；思政元素

\section{1.引言}

2016 年，习近平总书记在全国高校思想政治工 作会议中指出, “要坚持把立德树人作为中心环节, 把思想政治工作贯穿教育教学全过程, 实现全程育人、 全方位育人，努力开创我国高等教育事业发展新局 面。” ${ }^{[1]}$ 习总书记强调了高校思想政治工作的重要性, 同时指出要用好课堂教学这个主渠道, 除思政课程以 外, “其他各门课都要守好一段渠、种好责任田, 使 各类课程与思想政治理论课同向同行, 形成协同效 应” “ ${ }^{[1]}$, 这要求我们在高校教育工作中, 不能仅仅围 绕 “思政课程” 进行思政教育, 更要大力开展 “课程 思政”, 各学科都应充分发挥课堂教学在育人中的主
渠道、主阵地地位，从而将思政教育贯穿于学校教育 教学的全过程。

\section{2.大学英语课程思政教育的重要性}

大学英语作为学生步入大学校园后, 通识教育中 的一门重要必修课程, 具有人文性、工具性的双重特 点, 在帮助学生拓宽国际视野、培养跨文化交流能力 方面有着不可或缺的作用。

在传统的大学英语教育中, 存在 “重技能, 轻文 化” 的现象。由于应试教育的惯性思维, 课堂教学中, 教师更注重于考试技巧的讲授, 学生则专注于大学英 语四六级等考试的习题, 使得课堂内容僵化, 英语学 
习片面化。大学英语课程教材的内容, 多选取与英语 国家相关的素材, 学生在学习的过程中, 难免会受到 外来文化的冲击。教师在教学过程中必须有意识地融 入我国文化相关内容, 使学生将本国文化与外国文化 进行多方面比较, 避免出现文化盲从, 正确引导学生, 使其能够用批判、辩证的眼光去看待英语国家文化, 同时也帮助学生在对外交流中扫清障碍, 增强自信, 改变英语国家文化单方面渗透的状态, 实现英语国家 文化与中国文化的双向交流与传播。因此, 深入挖掘 大学英语 “课程思政”元素对落实立德树人根本任 务的价值, 拓展大学英语课程在知识、思想和技能上 的功能, 对培养新时代中国特色社会主义建设需要的 人才, 具有举足轻重的作用。

\section{3. 大学英语课程中的思政元素}

作为新时代的大学生, 在对外交流的过程中, 要 能够坚定立场, 自信自豪地讲好中国故事, 这对于学 生的家国情怀、国家意识、底蕴修养、文化自觉以及 各方面的综合素质都是较大的考验。在大学英语课程 中设置思政元素时, 教师不能将 “思政” 片面地理解 为 “思想政治” 教育, 要放宽眼界, 深度探索, 以所 选用的教材为依托, 多角度地挖掘思政元素, 如盐在 水、润物无声地渗透思政内容。

\section{1 中国传统文化}

大学英语课程中, 所选取的文本、音视频等, 多 是关于英美国家文化、社会、历史等方面相关的内容, 其中不乏对于英美国家传统文化的介绍, 在教学过程 中, 教师可以从文本中提炼重点单词、短语、句式, 同时提供与之相关的中国传统文化, 让学员对该内容 进行介绍和讲解, 在知识由输入转为输出的过程中, 培养学生的文化意识, 同时增强学生的文化自信。

博大精深的中国传统文化为教学提供了丰富的 资源, 例如节日传说方面, 可结合中国传统节日, 或 传说寓言等内容, 让学员在习得相关词句后, 能够以 较为准确的语言, 介绍节日的由来, 神话传说中人物 的故事等; 名家经典方面, 在讲解某一观点时, 可以 将相关的英文版本中国诗词、经典选段、名人名言等 作为导入, 进一步阐释该观点, 同时可将同一思想的 中、英版本进行对比, 讲解英汉语言的差异。例如可 以从《论语》中选取相关名言, 讲解在中国影响深远 的儒家思想; 传统艺术方面, 中国传统艺术不胜枚举, 书法、武术、建筑、戏剧、国画……这些艺术瑰宝 与西方艺术相比毫不逊色, 且许多元素为中华民族独 特的符号, 在教学过程中引入相关内容, 彰显中华传 统文化艺术在世界艺术殿堂中的重要地位, 可增强学 生的民族自豪感。

\section{2 习近平新时代中国特色社会主义思想}

作为马克思主义中国化的最新成果, 习近平新时 代中国特色社会主义思想高瞻远瞩, 涵盖了新时代坚
持和发展中国特色社会主义的总目标、总任务、总体 布局等基本问题，是全党全国人民为实现中华民族伟 大复兴而奋斗的行动指南, 新时代的青年学生应了解 其丰富的内涵。在授课过程中, 可结合 “八个明确” , “十四个坚持” 等内容, 帮助学生进一步熟悉习近平 新时代中国特色社会主义的精神实质, 使学生不仅有 文化自信, 更要有道路自信、理论自信和制度自信。

在选取相关素材时, 可关注习主席的各类重要讲 话的英译版, 从中摘取符合课程主题的部分, 作为授 课内容的升华。例如《新视野大学英语读写教程》(第 三版）第一册第二单元 “loving parents, loving children”, 该单元主题与亲子关系相关, 同系列第 二册第三单元翻译练习主题为 “孝道”, 这两个单元 均可以引用习近平主席关于孝文化的论述, 例如习近 平在十八届中央政治局进行第三十二次集体学习时 指出 “ 敬老爱老是中华民族的传统美德。要把弘扬 孝亲敬老纳入社会主义核心价值观宣传教育, 建设具 有民族特色、时代特征的孝亲敬老文化。”

此外, 也可深度挖掘政府工作报告等内容, 例如 可以从十九大报告英文版中选取相关例句, 讲解其中 的单词、句式、语法等内容, 同时进一步解读其精神。

例如, 在讲解 “stability”, 一词时, 可选取 该例句 “更加自觉地维护我国主权、安全、发展利 益, 坚决反对一切分裂祖国、破坏民族团结和社会和 谐稳定的行为” , 结合讲解常用短语 “社会和谐稳 定” - “social harmony and stability”，同时可 以讲解该句中的其他搭配，从而拓展词汇，并由此句 引申出十九大报告中提出的新时代应该做到的 “五 个更加自觉”。

\section{3 思维方式, 思考能力}

随着高校学生参与国际交流日臻频繁, 以及由此 带来的沟通问题日益增多，在大学英语的课堂上应该 加入 “应该是这样” 和 “为什么应该是这样” 的思

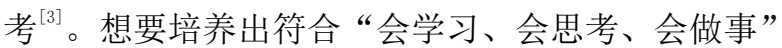
三会标准的新时代人才, 更需要注重对于学生思维方 式以及思考能力的培养。在教学中, 教师可设置相关 情景, 提出开放性问题, 营造良好的交流氛围, 引发 讨论并予以一定的指导, 使学生在思维的碰撞中做出 更好的判断, 避免盲从。

批判性思维如今被视为一项重要的思维能力, 也 是大学教育的重要目标之一。大学英语课程所涉及的 西方国家文化内容较多，其中政治、经济体制、历史 事件, 无不需要运用批判性、辩证性的思维去分析。 此外, 当今国际局势错综复杂, 疫情期间西方主流媒 体的报导, 各家言论的声音, 都需要学生清醒、客观、 理性地去看待。教师在授课过程中, 可设置辩论赛、 演讲比赛等环节, 使学生在完成任务的过程中锻炼自 己分析、评估、推论等思维能力。例如, 《新视野大 学英语读写教程》(第三版) 第二册第六单元主题为 “Less is more”, 可引导学生讨论, 如何理解 “少 
即是多”，探讨多与少的辩证关系，以及如何做出更 明智的选择。

创新思维也是新时代的要求之一, 国家需要具有 创新能力的高素质人才, 这就要求教师在传递基础知 识和训练学生基本技能的同时, 要注意培养学生的创 新思维, 使学生为发展自己的思维而学, 教师为发 展学生的思维而教 ${ }^{[4]}$ 。教师在授课中要注意激发学生 的创新意识, 秉承以学生为中心的思想, 在课堂中赋 予学生一定的自主权, 让学生有发挥的空间, 使学生 乐于创新、敢于创新。同时结合信息化教学手段, 利 用线上教学平台, 为学生搭建获取最新知识的脚手架。

\section{4 职业身份，使命担当}

大学生在毕业后将走入社会的各个行业, 教师应 在大学期间帮助学生树立职业理想, 使学生意识到自 己使命在身。教师在授课过程中, 可结合学生专业特 点, 选取该行业最新新闻动态, 展望未来发展前景, 也可选取该行业杰出的人物事迹, 为学生树立楷模榜 样。

例如, 在讲授《新视野大学英语读写教程》(第 三版）第一册第四单元 “Heroes of our time” 时, 军校教员可以列举我军的英雄, 激励学员学习其英勇 无畏、勇于牺牲的精神; 当授课对象是医学生时, 教 师可列举疫情期间奋战在抗疫一线的医生英雄, 如钟 南山、李兰娟等人, 引导学生感悟其职业精神。除以 上例子之外, 在各行各业, 都有值得称颂的英雄。第 五单元 “Winning is not everything”, 对于体育 专业的学生, 可以引导其思考什么是体育精神, 体育 竞赛中胜利是否是唯一的目标, 讲授过程中可以加入 我国奥运健儿的事迹, 学习他们坚忍不拔、顽强拼搏 的精神。同系列第二册第一单元 “Language in mission”，亲子之间关于英语学习的小故事可以给 师范专业的学生以启迪。文中父亲所采用的循循善诱 的教学方式激发了儿子的学习兴趣, 使枯燥的语法教 学变得生动有趣。教师在讲授该单元时, 可引发师范 生进一步思考, 如何进行启发式教学, 如何提高学生 的学习积极性。有针对性的实例更贴近学生未来的职 业, 更有助于增强职业认同感, 激发职业荣誉感, 从 而更好地完成自己的职业使命。

\section{4.提高挖掘思政元素的能力}

“传道者自己首先要明道、信道。思想政治工作 者要坚定理想信念, 努力成为社会主义先进文化的传 播者、我们党执政的坚定支持者, 不断增强做好思想 政治工作的定力。” ${ }^{[5]}$ 因此, 进行思政育人之前, 首先要增强高校教师的思政素养, 高校可对各专业教 师进行思政培训。教师的思政育人能力与其专业能力 同样重要, 要保证教师具有坚定的政治立场, 有信仰 的人才能讲好信仰, 有信仰的人才能感染学生坚定信 仰。身教重于言传, 教师只有提高自身的思想觉悟, 才能做好育人工作。
此外, 教师应增强对于当代大学生的了解。如今, 零零后大学生成长于信息爆炸的时代, 受到多元文化 的影响, 思想开放, 兴趣广泛, 思想较为独立。教师 应深入学生, 主动了解青年人的思想, 在设置教学中 的思政元素时, 结合学生的兴趣点, 以更易于学生接 受的方式有效地进行切入, 使思政元素融入的更加自 然, 避免教学内容和思政内容两张皮的现象。

同时, 要提高自身对于思政元素的敏感性。时刻 关注可以融入到课程中的思政元素, 提高思政素材的 时效性, 避免老生常谈, 以便增加学生的兴趣, 提高 话题讨论的参与度。授课中可将当下的社会热点、国 际时事等内容结合到课程中, 引发学生讨论和思考, 例如, 在讲授《新视野大学英语读写教程》(第三版) 第一册第七单元 section A “When honesty disappears”一文时, 可以将 “翟天临不知知网为何 物” 的事例作为导入, 引发学生对于学术不端行为的 讨论。

\section{5. 结论}

在国际交流日益频繁的今天, 大学英语不仅能够 帮助学生开拓眼界、了解世界, 更是学生对外展示中 国形象的重要工具。作为大学英语教师, 既要保持英 语课堂的 “专业属性”, 又要突出其 “思政功能” ${ }^{[6]}$, 这就需要不断提高自身教学能力以及思政育人能力, 在思政元素的挖掘上下足功夫, 实现思政元素与英语 学科内容的有机结合。

\section{REFERENCES}

[1] Xi Jinping. Taking the ideological and political teaching into the whole process of education and creating a new prospect for the development of higher education in China[N]. The People's Daily, 2016-12-09.

[2] Xia Wenhong, He Fang. The mission of ideological and political theories teaching of College English[J]. People's Forum, 2019, (30): 108-109.

[3] Wang Zhijie. The practice of critical thinking in College English Reading Class -- a review of critical thinking teaching and learning $[\mathrm{J}]$. Higher Education Exploration, 2019, (10): 140.

[4] Ke Jiangning. Innovative thinking cultivation in College English teaching[J]. Journal of PLA Nanjing Institute of Politics, 2010, 26(01): 116-117.

[5] Wang Yongyou, Yi Peng. Building an excellent ideological and political work team in Colleges and universities $[\mathrm{N}]$. The People's Daily, 2017-2-13.

[6] Du Gangyue, Sun Ruijuan. Research on effective strategies in ideological and political theories teaching in College English[J]. Journal of Yan'an University (SOCIAL SCIENCES EDITION), 2019, 41(04): 122-126. 